\title{
LA PROMESA DE FELICIDAD EN PROUST Y MIRÓ
}

\author{
THE PROMISE OF HAPPINESS IN PROUST AND MIRÓ
}

Matei CHIHAIA

Bergische Universität Wuppertal

Centro Interuniversitario de Estudios Culturales Hispánicos chihaia@uni-wuppertal.de

Resumen: A menudo se han comparado las obras de Marcel Proust y de Gabriel Miró. Las afinidades estéticas de los dos autores contemporáneos se pueden entender a partir de sus modelos comunes decimonónicos. Entre ellos, Stendhal ocupa un lugar especial. Su sentencia sobre la belleza como una «promesa de felicidad» que cambia según el tipo de felicidad esperado en diferentes épocas y lugares, aparece en varios pasajes de À la recherche du temps perdu y de El obispo leproso. El uso narrativo del aforismo estético le añade nuevos contextos: mientras que Proust lo interpreta a la luz del impresionismo y a la sombra de la antropología moralista, Miró contrasta la «promesa de felicidad» con la promesa de salvación cristiana.

Palabras clave: Marcel Proust; Gabriel Miró; Stendhal; Paul-Jean Toulet; promesa; felicidad.

\begin{abstract}
The works of Marcel Proust and Gabriel Miro have often been compared. The two contemporary authors share aesthetic ideals that are grounded in their common readings of NineteenthCentury classics. Among those, Stendhal deserves particular attention. His statement about beauty being a «promise of happiness» that changes with the type of happiness expected in different times and places, appears in several parts of $\grave{A}$ la recherche du temps perdu and El obispo leproso. The narrative use of the aphorism on aesthetics adds new contexts to it: while Proust interprets it in the light of impressionism and under the shadow of moralist anthropology, Miró contrasts the «promise of happiness» with the Christian promise of salvation.
\end{abstract}

Keywords: Marcel Proust; Gabriel Miró; Stendhal; Paul-Jean Toulet; promise; happiness. 


\section{1}

\section{La estética de la felicidad}

«La busca de la felicidad es uno de los temas importantes de la novela», escribe Jo Yoshida sobre En busca del tiempo perdido. «El texto está lleno de términos que evocan más o menos la idea de felicidad: dicha, bienestar, gozo, deleite, euforia» (2004: 160; la traducción es mía). También es conocido el lugar destacado del tema de la felicidad en la obra del contemporáneo alicantino de Proust: «Todos los temas y subtemas que Miró trata se pueden resumir en uno central: el problema del hallazgo de la felicidad» (cf. Ontañón de Lope Blanch, 1974: 664). Ninguna de las numerosas comparaciones de estos autores (cf. Vidal, 1934; Baquero Goyanes, 1952, 9-10; Van Praag-Chantraine, 1958; Guillén, 1969; Lozano Marco, 2010: 35; Craig, 2012: 47-51) se han dedicado todavía con el detalle debido a la dimensión estética del tema de la felicidad, aunque el estado de la cuestión aparece muy avanzado en ambos casos. El resumen de Yoshida destaca tres aspectos de la felicidad en la obra de Proust: lo efímero del placer sensual, la parte de la imaginación que se moviliza sobre todo al alejarse las personas queridas, y el cumplimiento de la obra literaria, siempre aplazado (2004: 160). La materialidad de las sensaciones en Miró ha sido contrastada con los gustos impresionistas de Proust (cf. Baquero Goyanes, 1948: 90-93); se ha explicado porque la 'promesa de felicidad' en las novelas de Oleza, expresa el sentimiento trágico de una felicidad inalcanzable (Coope, 1984: 169). Sin embargo, hasta ahora falta un estudio intertextual de la 'promesa de felicidad', tema recurrente en los dos autores contemporáneos.

Este motivo pertenece a la literatura decimonónica francesa, con la que tanto Proust como Miró se habían familiarizado por sus lecturas extensas. Me refiero a un aforismo de Stendhal que se encuentra, por ejemplo, en la segunda edición de su libro de viajes sobre Roma, Nápoles y Florencia (1826): «La belleza no es nunca otra cosa que una promesa de felicidad» (1955: 474; cit. en Juárez, 2014: 124). Stendhal no se refiere solamente a la seducción erótica, aunque la frase citada expone la atracción del viajero por las mujeres italianas. En realidad, esta definición se adapta a unos contextos diferentes, y puede abarcar amor, sociedad, historia y política. Prolonga la discusión fundamental del clasicismo francés, la Querelle des Anciens et des Modernes, que había arrancado más de un siglo antes. En esta discusión, la idea de una belleza relativa que sustituye el ideal eterno de los modelos antiguos va más allá de la teoría del arte o de la estética: sirve para reivindicar los logros de la cultura moderna, la posibilidad de un cambio y la legitimidad de lo diverso.

Para Stendhal también, el relativismo estético incluye una dimensión culturalista y hasta política. En su Historia de la pintura en Italia, publicada en 1817, comenta que las formas de las mujeres, en una república anuncian la felicidad («bonheur»), en una monarquía, el placer («plaisir») (1817: 148; cap. CXIV). También explica, en una nota al pie de página del capítulo CX, la diferencia de los gustos, con respecto a una diversidad histórica, geográfica y cultural: la belleza manifiesta una forma habitual de buscar la felicidad; por lo tanto, el amigo que nos agrada en un baile de París no es el que 
necesitamos en las selvas americanas (1817: 130). En su libro Del amor (1822), donde el contexto sigue siendo la distinción de la belleza antigua y de la belleza moderna, añade un ejemplo semejante: «la beauté n'est que la promesse du bonheur. Le bonheur d'un Grec était différent du bonheur d'un Français de 1822»(1906: 34). Esta idea, tan original con respecto a las estéticas clasicistas, emplea un recurso estilístico practicado mucho en los aforismos de los llamados Moralistes clásicos y vinculado estrechamente con su pesimismo antropológico. Es sobre todo el duque de La Rochefoucauld quien plasmó el modelo estilístico de esta reducción radical. El «n’est que», el «no es nunca otra cosa que», sirve para explicar la determinación del ser humano por pulsiones exclusivas como, por ejemplo, su orgullo. Roland Barthes llama a esta figura de estilo de La Rochefoucauld «relation d'identité déceptive», y le da la forma estructural de «A n'est que B» (1972: 69-88). El aforismo de Stendhal evoca este tipo de reducción cuando insiste, en varios contextos, sobre la relatividad de la belleza. Conviene agregar, pues, la antropología de los Moralistes a los horizontes de su famoso aforismo. Sin embargo, las consecuencias de esta sentencia van también más allá de la ética pesimista del amor.

El lugar primordial que ocupa la felicidad en la tradición francesa a partir de Stendhal contrasta radicalmente con la tradición del pensamiento alemán, hostil a la felicidad (cf. Gabriel, 2011: 106117). El rechazo del placer sensual es acentuado por el idealismo. Aunque toda la estética idealista coloca la belleza en el centro de sus sistemas, esta meta suprema del arte no se concibe sin un trasfondo metafísico; al contrario, para Stendhal, la belleza no es sino un producto de una esperanza individual, de un deseo de felicidad efímero (cf. Juárez, 2014). Esta idea entronca, por lo tanto, con el entusiasmo por el regocijo sensual que expresa la literatura ilustrada en Francia (Mauzi, 1960; cf. Juárez, 2014: 130). La felicidad se convierte, a partir de esta revelación, en el centro transcendental del ser humano; es decir, que determina todo lo demás sin poder ser definido: «Es inútil definir la felicidad: todo el mundo la conoce», concluye el ensayo Del amor (1955: 863; cf. Juárez, 2014: 128).

Desde ahí, la atención que recibe la promesa de felicidad en dos autores aficionados a Stendhal: veamos las formas específicas que dan Proust y Miró a esta estética centrada en la dicha individual, cuyas propias raíces encontramos en la querella de los antiguos y de los modernos, en el estilo y la antropología moralista, y en el pensamiento sensualista.

\section{Lo efímero y lo inmediato}

En su gran composición narrativa, Marcel Proust cita varias veces a Stendhal sin nombrarlo. De hecho, la cita ubicada en el último capítulo de Por el camino de Swann (1913) ni siquiera se manifiesta como tal, sino que llega casualmente en el marco de una larga reflexión acerca de la felicidad. Una segunda cita aparece con referencia a un «se ha dicho» y se encuentra en medio del relato del amor desdichado del narrador por Albertina, en la parte que se titula La prisionera (publicada tras la muerte del autor, en 1923). La distancia de los dos pasajes abre una disyuntiva típica de la obra de Proust: Por el camino de Swann cuenta la historia de la infancia y la ilusión que le producen las primeras 
experiencias de la memoria involuntaria: experiencias de regocijo intenso e incomparable como la de los trocitos de magdalena mezclados con la tila. La prisionera, en cambio, escrita hacia el final de la vida de Proust, trata la desilusión del protagonista con la sociedad, con el arte y con el amor. La amargura de estas partes que desembocan en la huida y muerte de Albertina, La desaparecida, contrasta notablemente con el estado de ánimo del primer tomo. El profundo desasosiego que le produce al narrador su relación con Albertina supera la ilusión estética anunciada por el sabor de la magdalena. Al mismo tiempo, la repetición de la cita recuerda la semejanza entre la relación que vincula al narrador con la misteriosa Gilberta, el amor de su infancia, que anhela encontrar en sus paseos en los Campos Elíseos parisinos, y su amor adulto y obsesivo por Albertina, cuyo nombre incluso se confunde con el de Gilberta en algunas ocasiones.

En Por el camino de Swann, el narrador niño, perturbado por un gesto misterioso de su amiga Gilberta, que ha despertado en él un deseo que él mismo no comprende del todo, espera inquieto los paseos en el área de los Campos Elíseos: allí espera un encuentro casual con su amiga. Pero además de si estará la niña le preocupa el clima: porque un cielo nublado significa la cancelación del paseo, y por ende la frustración de todos sus anhelos. Por ello escudriña los reflejos de luz en la piedra y en la baranda de su balcón, que dibujan en estas superficies la silueta de una yedra efímera:

Yedra instantánea, flora parasitaria y fugitiva, la más incolora, la más triste, y con mucho de todas las que pueden trepar por una pared o adornar una ventana; yedra para mí más cara que todas desde que apareció en el balcón como la sombra misma de Gilberta, que quizá estaba ya en los Campos Elíseos, que me diría en cuanto yo llegara: «Vamos a empezar a jugar a justicias y ladrones; usted está en mi bando»; yedra frágil, que un soplo arrancaba, pero que no dependía de la estación del año, sino de la hora; promesa de la felicidad inmediata que el día niega o concede, de la felicidad inmediata por excelencia, de la felicidad del amor; yedra más suave y más cálida allí en la piedra que el fino musgo; yedra viva que con un rayo de sol nace y da alegría hasta en el mismo corazón del invierno.

Y aún en aquellos días en que desaparece toda la demás vegetación, cuando el hermoso cuero verde que sirve de funda a los árboles viejos está oculto por la nieve, si dejaba de nevar, el sol solía asomar de pronto, entretejiendo hilos de oro y bordando reflejos negros en el manto de nieve del balcón, y aunque el tiempo seguía muy nublado, y no era de esperar que Gilberta saliese, mi madre me decía: «Ya hace bueno otra vez; podías probar a ir un poco a los Campos Elíseos» (Proust, 2015: 512-513).

La yedra, en este pasaje, aparece con un propósito múltiple. A nivel de la descripción nos permite imaginar la realidad material de las sombras y luces dibujadas por el sol que asoma tras las nubes. Esta misma imagen contiene, a nivel alegórico, una poderosa tradición que hace de esta planta casi inmortal un signo del amor eterno, anunciado también por el nombre de los Campos Elíseos, lugar de dicha eterna en la mitología romana. Sin embargo, el narrador interpreta este simbolismo paradójicamente cuando recuerda que la yedra suya no es la que pervive en todas las estaciones, sino una planta tan fugaz como los cambios de la luz y de los sentimientos. En otras palabras, Proust pinta en este pasaje un cuadro impresionista en el que logra captar un juego efímero de luces y sombras.

Este juego enmarca la cita de Stendhal y produce un nuevo conjunto de ideas: la «promesa de la felicidad»se refiere a una «felicidad inmediata por excelencia»; en esta inmediatez coinciden, de hecho, la promesa y la felicidad. Tanto para el niño como para el narrador, la impresión de yedra creada por un rayo de sol proporciona un estado eufórico que sustituye al paseo, que el mismo no es sino un 
anuncio de un posible encuentro con Gilberta, encuentro que no es sino un avance hacia el misterio deseado... El regocijo inmediato es una promesa autocumplida. En esto, el pasaje comentado recuerda la experiencia fundamental de este primer tomo de En busca del tiempo perdido, la promesa recibida por el sabor de la magdalena.

El regocijo experimentado por el joven en el instante de saborear la mezcla de magdalena y tila caliente es más que el anuncio de una felicidad futura, que le proporcionará la memoria involuntaria, el recuerdo perfecto del pasado. Este regocijo es otro ejemplo de la «felicidad inmediata». La cascada intensamente sensual que brota de aquella cucharilla de tila contiene ya todo el placer, un placer de origen desconocido. En este placer coinciden la promesa de la felicidad con la propia felicidad; esta coincidencia está estrechamente vinculada con la aceleración de las sensaciones. Más que la divergencia de los antiguos y de los modernos, el relativismo estético de este pasaje radica en la riqueza inigualable de cada instante. Mientras que Stendhal piensa en la belleza específica de una época, Proust concibe la 'promesa' como la posibilidad de una belleza instantánea y eterna al mismo tiempo.

\section{La incertidumbre del cumplimiento}

La fórmula de Del amor vuelve en el cuarto tomo de la novela de Proust, La prisionera, novela dedicada a la obsesión erótica y a los disgustos del amor. En una ocasión, el protagonista describe su deseo poco específico, repartido entre varias muchachas que encuentra en sus compras: lecheras, panaderas etc.; y que le atraen por meros detalles de su apariencia. Estos detalles son desvinculados de la idea de belleza, e incluso le desagradan a veces. Basta, en realidad, una alusión a la «coquetería» de una de las muchachas para excitarle con una promesa de goce erótico. El narrador concluye de esta experiencia que la felicidad puede prescindir, a veces, de la hermosura del ser deseado. El orden establecido por la sentencia de Stendhal, orden perturbado por la inmediatez de la estética impresionista, se ha prácticamente invertido; poco importa la belleza, mientras haya promesa de placer:

Una vez que entré en la mantequería a comprar queso, me llamó la atención entre las dependientas una verdadera extravagancia rubia, muy alta, aunque infantil, y que, en medio de las demás, parecía estar soñando, en una actitud bastante orgullosa. La vi sólo de lejos y pasó tan de prisa que no hubiera podido decir cómo era, sólo que había debido de crecer demasiado de prisa y que llevaba en la cabeza un toisón que daba idea, mucho más que de las particularidades capilares, de una estilización escultórica de los meandros aislados de unos ventisqueros paralelos. Sólo había distinguido esto y una nariz muy dibujada (cosa rara en una niña) en un rostro flaco y que recordaba el pico de las crías de buitre. Por otra parte, no fueron sólo las compañeras agrupadas a su alrededor lo que me impidió verla, sino también la incertidumbre de los sentimientos que, a primera vista y después, podía yo inspirarle, si de orgullo arisco, o de ironía, o de un desdén que expresaría después a sus amigas. Estas suposiciones que alternativamente hice sobre ella en un segundo, espesaron en torno suyo la atmósfera turbia en que se me perdía, como una diosa en la nube que el rayo hace temblar. Pues la incertidumbre moral dificulta una exacta percepción visual más de lo que pudiera dificultarla un defecto material de la vista. En aquella jovenzuela demasiado flaca que por eso llamaba más la atención, el exceso de lo que otro llamaría quizá encantos era precisamente propio para desagradarme a mí, pero, sin embargo, su resultado fue no dejarme ver nada, y mucho menos recordar, de las otras pequeñas dependientas, que la naricilla arqueada de ésta, su mirar pensativo, personal, como de juez —cosa tan poco agradable-, habían sumergido en la noche, como un rayo rubio que entenebrece el paisaje circundante. Y así, de mi visita para encargar queso en la mantequería sólo recordaba (si «recordar» puede decirse tratándose de un rostro tan mal mirado que, no teniéndole delante se le aplica diez veces una nariz diferente), sólo recordaba a la pequeña que me había desagradado. Esto basta para iniciar un amor. Pero habría olvidado a la 
extravagancia rubia y nunca deseara volver a verla si Francisca no me hubiera dicho que aquella pequeña, aunque muy jovenzuela, era despabilada e iba a dejar a la patrona porque, demasiado coqueta, debía dinero en el barrio. Se ha dicho que la belleza es una promesa de felicidad. Inversamente, la posibilidad del placer puede ser un comienzo de belleza (Proust, 1983: 148-149).

La cita es inexacta en tanto que omite la formulación reductora, el «n'est que»; le atribuye a Stendhal una visión más positiva, una aserción de lo bello que no supone ni el relativismo moderno ni el pesimismo de los Moralistes. Considero que necesita este cambio para aumentar el efecto de la inversión: a la visión estética del maestro contrapone una conclusión cínica, en la que una promesa de placer justifica la exaltación de lo feo. De la ecuación inversa, la felicidad ha desaparecido prácticamente, dando paso al goce: esta variación recuerda el pasaje de la Historia de la pintura en Italia sobre la correlación de los ideales estéticos con el tipo de gobierno (Stendhal, 1817: 148; cap. CXIV). Por cierto, en Proust la causa del cambio no es política. Para entender mejor esta transformación del ideal estético, debemos considerar que cierra un largo párrafo que describe la naturaleza turbia del deseo; algo que solamente estaba atisbando en su infancia y que se le va revelando poco a poco a partir de Sodoma y Gomorra. La promesa de felicidad, en estas páginas, se resume a un juego de seducción, y la belleza no es sino la manifestación de una pulsión individual.

Este pesimismo respecto al amor es bastante común en la literatura de comienzos del siglo XX. Proust no es el único autor francés que transforma la cita famosa de Del amor. Su contemporáneo Paul-Jean Toulet usa la misma formulación como él en dos de sus colecciones de aforismos. Primero, en el marco de su novela Monsieur du Paur, homme public (1898), que termina con una reproducción del cuaderno del protagonista: ahí encontramos una versión misógina de la sentencia de Stendhal: «On a dit que la beauté était une promesse de bonheur: en est-il de plus mal tenue s'il s'agit de beauté féminine?» (Toulet, 1986: 265) Tampoco le hace caso a la formulación original, al «n'est que» de Stendhal la segunda vez que lo cita con la misma intención, en el apartado «Mulier» de su propia recopilación de aforismos, Les Trois impostures: «On a dit de la beauté que c'était une promesse de bonheur. On n'a pas dit qu'elle fut tenue» (Toulet, 1986: 170). No es imposible que el encuentro con la mantequera coqueta sea una reminiscencia de este juego de palabras misógino, cuya primera parte coincide literalmente con la versión de Proust ( «Se ha dicho que la belleza es una promesa de felicidad.»). Sabemos que Proust había leído la poesía de Toulet (1971: 639), y Monsieur du Paur, homme public, novela ecléctica, recuerda las obras compuestas del joven Proust (sobre todo Jean Santeuil, durante cuya escritura sale la novela de Toulet). Por cierto, la función del aforismo en Proust no se debe desvincular de su ubicación en el marco de la 'busca del tiempo perdido': en este marco, la descalificación de la belleza femenina importa menos que la evolución de la propia visión estética del narrador.

La conclusión de Proust en el largo pasaje que citamos va más allá de la equiparación de felicidad y satisfacción sensual que se manifiesta en el capítulo sobre su espera y la yedra imaginaria. Ahora estriba en la «incertidumbre de los sentimientos», la «incertidumbre moral» en la «atmósfera turbia» que rodea a las muchachas, espesa niebla de la que sobresalen algunos rasgos físicos poco convincentes. La inmediatez de la experiencia como fuente de felicidad ha dado paso a la 
incertidumbre de esta experiencia con respecto a todo lo que no se intuye de forma sensual. De esta manera cambia la promesa de felicidad a lo largo de la novela: el regocijo causado por la inmediatez sensual contrasta con el placer proporcionado por la incertidumbre moral. Lo efímero de la felicidad que experimenta cuando era niño frente al juego de luces y sombras efímeras contrasta con lo profundamente ambiguo de esta felicidad, cuyas raíces yacen en la niebla nunca despejada de las relaciones humanas.

\section{4. «Seamos dichosos»}

La relación de Proust y Miró con los maestros decimonónicos es la causa principal de las semejanzas de sus obras (Craig, 2012: 48). Sabemos que Miró fue, como Proust, un lector de John Ruskin, cuya estética prerrafaelita dejó una impronta notable en su obra (Riera, 1988: 141-142), y un verdadero aficionado a Stendhal, autor leído, citado y anotado (Macdonald, 2010: 221-224): el ejemplar de Del amor en su posesión recibe cruces frecuentas en sus primeros treinta capítulos (Macdonald, 2010: 109). Podemos decir con certeza, pues, que Miró asimiló el capítulo XVII de Del amor, en el que una nota al pie de página define la belleza como «promesa de felicidad» y comenta la diferencia del sentimiento estético en los griegos (es decir, los antiguos) y los franceses del 1822 (es decir los modernos).

Así se explica que las ideas de Stendhal acerca de la felicidad aparecen en varios textos del autor alicantino, y que se relacionan con una experiencia del tiempo que puede recordar los pasajes citados de En busca del tiempo perdido. Hasta la Historia de la pintura en Italia, lugar donde se forja la idea sobre la historicidad del sentimiento estético, o sea la relatividad de la belleza comentada en la famosa nota de Del amor, cuenta para Miró. El primer texto que evoca, de forma implícita, la 'promesa de felicidad', es una estampa del Libro de Sigüenza (1917/1927) fechada en el año 1914, o sea, un año después de la publicación de Por el camino de Swann: «La fruta y la dicha». A pesar de su brevedad, este fragmento ha sido comentado y citado extensamente por la crítica. Van Praag-Chantraine lo compara con Proust por la relación entre el sabor y la memoria del pasado (1958: 290-291); Craig vuelve sobre ello para resaltar las diferencias, la brevedad de la descripción y la desvinculación de la experiencia sensual del yo: los frutos tienen su sabor a la disposición de todos (2012: 51). Guillén, finalmente, destaca la fe en las palabras que, para Miró, no solamente permiten obtener una consciencia intelectual de las cosas, sino también paladearlas: hasta la felicidad se da bajo la palabra del «seamos dichosos» (1969: 24):

Sigüenza, el alter ego de Miró, «se ha oído a sí mismo pronunciar 'seamos dichosos'. Y al decirlo comenzaba a serlo... Porque en aquellas palabras había un principio de voluntad y de conciencia de la dicha». Esta altura consciente, acompañada de decisión, no se consigue sino formulando una idea y pronunciando las sílabas en que esa idea se identifica a su forma. «Seamos dichosos» — concluye Miró- «constituye una aptitud y un propósito que nos acerca, que nos facilita la posesión de un conjunto, de un horizonte de sentimientos» [(Miró, 2008: 593)] (Guillén, 1969: 24). 
Me parecen sumamente acertadas las observaciones de Guillén, publicadas por primera vez en 1961 (Landeira, 1979): permiten comprender la forma específica que recibe la promesa en este texto. Es el voto «seamos dichosos» hecho en los «días frutales» que pervive, mientras que el hueso de albaricoque plantado por perpetuar aquel sabor se ha perdido (Miró, 2008: 593). La felicidad se nos presenta por una promesa que nos hacemos a nosotros mismos, y que transforma «la promesa evangélica» hecha a los humildes en las Bienaventuranzas (Miró, 2008: 594). Es este acto de habla, este acto poético, en el que se perfila el «instante bueno y emotivo» (Miró, 2008: 593) determinado por «la frescura y delicia de las cerezas y de los albaricoques» (Miró, 2008: 592). Por lo tanto, la estampa termina con un elogio de la imaginación poética, en la que pueden coincidir de forma inmediata la promesa y la posesión:

En nuestra vida y en lo que la rodea hay una honda claridad cuando queremos ser dichosos, y una atención serena que puede avenirse con la étourderie de Stendhal, y entrambas hacen que plantemos no sabemos dónde el hueso de una cereza, de un albaricoque que nos ha gustado mucho, para que nazca un árbol que tampoco sabemos si saldrá, pero que, desde luego, no nos dará su fruto ni su sombra. Y, sin embargo, lo imaginamos y poseemos: es el árbol más frondoso y abundante de todos los huertos... (Miró, 2008: 596597).

Este pasaje se refiere brevemente al capítulo CXIII de la Historia de la pintura en Italia que se dedica a diferenciar la belleza moderna de la belleza antigua: el término de «étourderie», o «descuido» es fundamental, según Stendhal, para comprender la gracia del arte moderno, cuidadosamente descuidada (Stendhal, 1817: 144-148). De la misma manera, para Miró, la actitud estética sabe conciliar los opuestos. En el voto de un instante dichoso coinciden atención y descuido, posesión e imaginación. El tópico de la estética del Siglo de Oro, que pide ya este 'descuido cuidadoso', recibe una nueva interpretación en clave moderna: Sigüenza «prorrump[e]» «seamos dichosos», y esta manifestación de una felicidad efímera es, como en el pasaje citado de Swann, una profecía autocumplida.

Sin embargo, el placer proporcionado por la sensación de los objetos no depende, como en Proust, de la impresión subjetiva: las habitaciones y los paisajes de Miró existen fuera de la memoria, y cada matiz se agrega a una realidad fenomenológica cuyo ser transciende la percepción del yo. Ya los primeros críticos como Vidal (1934: 55), cuya tesis es defendida en 1934 (Landeira, 1979) compararán los dos autores principalmente para poner de relieve su diferencia. Baquero Goyanes, en su magnífico panorama de la novela moderna del 1948, enfatiza la contraposición: «No sé cómo puede haberse hablado de un impresionismo mironiano. El impresionista recoge el latido fugaz de un color, el perfil tembloroso de unos objetos disueltos en una luz cambiante y deformadora» (1948: 92). Mientras que Proust, según Baquero Goyanes, se dedica a la pormenorización de los hechos psicológicos, Miró explora la espesura sensual del mundo: «Hay que acercarse a las cosas, apretarlas entre las manos, sentir su dureza o su ternura, su calor o su frío en la piel; aspirar su perfume, gustar su sabor» (1948: 92). A la eternidad del instante que pervive en la 'memoria involuntaria' del yo proustiano se contrapone, en la obra del autor alicantino, la intuición de la eternidad de la naturaleza: «ríos, piedras, árboles, cielo parecen existir desde siempre y nos hablan con voz de perdurabilidad» 
(Baquero Goyanes, 1948: 93). Estas diferencias son también consecuencia de las formas narrativas elegidas por los dos escritores: a la subjetividad de la primera persona en Proust le contesta la objetividad de un narrador impersonal en Miró. Hasta la narración autobiográfica del Libro de Sigüenza, de la que citamos «La fruta y la dicha», se transmite en tercera persona, por medio del protagonista Sigüenza, formado, como dice el prólogo al lector «a mi imagen y semejanza» (Miró, 2008: 477).

\section{5. «La salvación y la felicidad»}

Esta postura narrativa acarrea otro contexto de la 'promesa de felicidad', y permite que Miró haga hincapié en la dimensión socio-política de la belleza, presente en Stendhal, pero ocultada por las tribulaciones del yo proustiano. Hemos comentado brevemente la alusión al Evangelio y la promesa de salvación hecha en el Sermón de la montaña. ¿Cuál es el lugar de esta promesa en el conjunto de fuerzas contrapuestas a la felicidad? En las obras de Miró, la institución de la Iglesia, su doctrina dogmática y la crueldad de algunos curas son representadas como verdaderos obstáculos a la felicidad (Ontañón de Lope Blanch, 1974: 665-667). Sin embargo, el elogio de la humildad como se pronuncia en las bienaventuranzas y la ilusión de salvación quedan vinculados estrechamente no solo con el alter ego Siguienza, sino también con los dos personajes más positivos de El obispo leproso (1926), Pablo y su madre Paulina. Tras haber confesado su amor extraconyugal por María Fulgencia al obispo en el claustro, Pablo se siente salvado y feliz en un sentido muy cristiano: «Felicidad nueva. Todo rodeándole para que él lo poseyese. Así contemplaría el primer hombre la creación intacta delante de sus ojos y de sus rodillas» (Miró, 2008: 447). Su madre, Paulina, también busca la salvación en la catedral, según las palabras de la misericordia «Llamad y se os abrirá» (Miró, 2008: 454); pero fracasa frente a la institución «fría y rigorosa», donde el obispo está agonizando (íbid.). De esta forma, el fracaso de la promesa de salvación cristiana da paso a promesas de felicidad profanas, que vertebran el desenlace de la novela y brindan un nuevo sentido a la querella de los antiguos y de los modernos.

La idea de Stendhal pierde, en estos contextos mironianos, todo sobreentendido misógino. Al contrario de la tradición francesa, las dos protagonistas principales, Paulina y María Fulgencia, son receptoras, y no emisoras de promesas de felicidad no cumplidas. En el caso de Paulina, esta promesa se desprende de un conjunto material de objetos. Son los muebles de su casa paterna, el «Olivar» y los de la casa de su marido en Oleza que rivalizan en sus propuestas respectivas; por esto Paulina sonríe con amargura «a la promesa de felicidad» pronunciada por su marido cuando este anuncia el retiro de la familia al campo:

En el «Olivar» les esperaban los muebles suyos: las cómodas de olivo, los armarios de ciprés, los lechos de columnas de caoba, los candelabros de roca, los espejos románticos, las consolas, los relojes, los alabastros... Y según iba recordando sus contornos, sus calidades, y pronunciándolo, adquirirían configuraciones y semblantes de vacilación. Todo aquello y los muros y envigados de los ámbitos de la casona y los árboles, la tierra y el aire y el silencio, todo pertenecía a su legítimo pasado, a su sangre y, por tanto, a su hijo; todo estuvo aguardando la felicidad de la heredera desde antes que ella naciese. Y todo quedó en un olvido de repudio por la voluntad de Don Álvaro, el amo nuevo. El «Olivar» se desaromó de su recogimiento; se cerró el casalicio, fraguándose el ambiente del desamparo, conformándose en la desgracia. 
¿Se despertaría jubiloso ahora, uniéndose a una súbita felicidad que no era de allí? [...] ¡Cómo sería esa felicidad, una felicidad que, para serlo, había de desvertebrarse de la felicidad que cada uno se había prometido! (Miró, 2008: 456).

Como una parodia del modelo de salvación evocado por su hijo, la madre pone en duda la posibilidad de una vuelta al paraíso perdido de la infancia: las promesas de felicidad son múltiples y contradictorias, y cada promesa cumplida supone otro compromiso fracasado. Pervive en este relativismo amargo la idea de belleza moderna, relativa, expresada por Stendhal en su célebre fórmula. Esta incertidumbre estética se extiende al campo de la religión: entre los muebles destacan los objetos de una devoción y las estatuas de Nuestra Señora, cuyas promesas no cumplidas agobian a Paulina (Miró, 2008: 455).

En relación con esta idea, pronunciada de forma general por Paulina, la carta de María Fulgencia especifica la promesa con respecto a la escultura de Francisco Salzillo, al Ángel que para ella era un anuncio de su felicidad posible con Pablo:

¡Se acabó —como suele decir el señor deán一, se acabó el Ángel! Fue la promesa de mi felicidad. Yo lo buscaba, yo lo adoraba; quise ser su velada o su santera. Nunca me propuse que las cosas fuesen mías, sino yo de ellas. Por eso parezco tan antojadiza. Me rodeaba de estampas y de recuerdos de mi Ángel, y el Ángel fue la promesa de Pablo. [...] Ya no voy a ver el Ángel. Ahora todos los días me asomo a mi terrado para mirar el tren de Oleza, el que sale de Murcia a Oleza. Tan lejos se quedó mi Oleza, que ya tiene tren, y con las mulas de mi labranza y un faetón de mis abuelos fui de este casón a la felicidad. [...] Ya no pasará nada. Se lo juro, porque ahora ni su hijo podría volverme a la felicidad de antes (Miró, 2008: 459-460).

La contraposición de la obra de arte del Siglo de Oro y del ferrocarril no es solamente una alusión a las estéticas de lo antiguo y de lo moderno y al conflicto entre la religión y el progreso: como para Paulina, la promesa no cumplida de la belleza quita la posibilidad de volver a la felicidad en su estado de inocencia. En este desenlace, la «promesa de felicidad» no es sino una causa de amargura y desencanto, la belleza relativa, materializada en la oposición del tren y del faetón, se contempla sin emoción, lejos del entusiasmo de los modernos (compartido por Stendhal), como prueba de una felicidad imposible. Coope, a quien debo el descubrimiento de estas recurrencias, afirma que «happiness is almost never in the present tense but in the past or future» (1984: 169). Sobre el trasfondo intertextual se comprende el pesimismo profundo de esta visión: la dicha esperada por el pasado ahoga la ilusión del futuro.

\section{Dos interpretaciones de Stendhal}

Notamos cómo los dos autores convierten la fórmula de Stendhal, breve aforismo al pie de página, en un efecto narrativo de largo aliento. Para Proust como para Miró, el potencial de la «promesa de felicidad» es doble: por un lado, celebran la profecía autocumplida de un presente experimentado con inmediatez, en el mundo de los sentidos; por otro lado, lamentan lo relativo de unas promesas que por su ambigüedad o multiplicidad no se pueden cumplir nunca. Las dos visiones contrapuestas se manifiestan, para los dos autores, en textos separados por un intervalo considerable, que puede explicar el cambio de actitud. En el caso de Proust, Por el camino de Swann se publica en 1913, y La Prisionera 
solamente se edita en 1923. Miró escribe «La fruta y la dicha» en 1914, y publica El obispo leproso en 1926. La doble interpretación de la promesa — como ocasión de euforia o de desencanto- me parece el principal punto de convergencia entre los dos autores.

Sus obras también ponen de relieve la riqueza del pensamiento de Stendhal cuando resaltan matices diferentes de la «promesa de felicidad». Proust convierte la idea de una belleza relativa, moderna, en la celebración de lo efímero; la promesa específica de una época (antigua o moderna) y un territorio (Grecia, Italia, Francia o América) se reduce, en las páginas de Por el camino de Swann en la belleza única de un instante y del entorno sensual del yo en este momento. La prisionera, luego, enhebra con el pesimismo antropológico que Del amor hereda de los Moralistes: la «promesa de felicidad», cuyo cumplimiento parece imposible por la incertidumbre física y moral frente a los objetos de la pasión, da paso a un anhelo de placer físico, a un deseo de posesión. Si En busca del tiempo perdido hace de la atracción erótica una metáfora del gusto estético, abandona el contexto principal de Stendhal, es decir, la Querelle des Anciens et des Modernes, a favor de un análisis psicológico.

Miró, en cambio, rescata este contexto socio-político de la «promesa de felicidad»: proyecta el goce sensual sobre el trasfondo de la poética del Siglo de Oro, en la que se concilian la atención y la «étourderie», el rigor de los antiguos y la despreocupación de los modernos, en la fórmula del descuido cuidadoso. En su narrativa se manifiesta una tensión entre la promesa de salvación de la doctrina cristiana y la promesa de felicidad del mundo profano: mientras que la primera sugiere la posibilidad de reintegrar el paraíso perdido como un estado de felicidad fuera del tiempo, la visión más realista del segundo considera la relatividad de las propuestas hechas en momentos distintos y lugares diferentes como un obstáculo insuperable. Las «promesas de felicidad» contradictorias se anulan y resultan en un estado de vacío emocional. Las narraciones de Miró interpretan, de esta forma, la estética de Stendhal como un rechazo de la ilusión romántica; hacen hincapié en su realismo y se alejan, al mismo tiempo, de la postura misógina de los franceses. Mientras que Proust ubica la frase de Stendhal en el contexto del yo, autor de euforias e incertidumbres, Miró la traslada al mundo de los objetos, fuente de placer y desgarro.

\section{Bibliografía}

BAquero Goyanes, Mariano (1948): «Tiempo y “tempo" en la novela», Arbor, 11/33, pp. 85-94. (1952): La prosa neomodernista de Gabriel Miró. Murcia, Real Sociedad Económica de Amigos del País.

BARTHES, Roland (1972): Nouveaux essais critiques. París, Seuil.

Coope, Marian G. (1984): Reality and Time in the Oleza Novels of Gabriel Miró. Londres, Tamesis.

CRAIG, Herbert E. (2012): The Reception of the Writings of Marcel Proust in Spain. Translations, Literary Criticism, and Narrative Influence. Lewiston, The Edwin Mellen Press.

GABRIEL, Nicole (2011): «Malaise dans la civilisation et promesse de bonheur. Freud et Adorno», Savoirs et Clinique, 1/13, pp. 106-117. 
GuILlÉN, Jorge (1969): En torno a Gabriel Miró. Breve epistolario. Madrid, Ediciones de arte y bibliofilia.

JUÁREZ, Esteban Alejandro (2014): «La belleza como promesse du bonheur. Algunas notas sobre su origen en Stendhal», En-claves del Pensamiento, 8/15, pp. 123-146.

LANDEIRA, Ricardo (1979): «Tres cuartos de siglo de crítica mironiana», en J. L. ROMÁN DEL CERRO, ed., Homenaje a Gabriel Miró. Estudios de crítica literaria. En el centenario de su nacimiento (1879-1979). Alicante, Publicaciones de la Caja de Ahorros Provincial, pp. 265-281.

LOZANO MARCO, Miguel Ángel (2010): Los inicios de la obra literaria de Gabriel Miró: Del vivir. Alicante, Universidad de Alicante.

MACDONALD, Ian R. (2010): Gabriel Miró. Su biblioteca personal y su circunstancia literaria. Trad. Guillermo Laín Corona. Alicante, Universidad de Alicante.

MAUZI, Robert (1960): L'Idée du bonheur dans la littérature et la pensée françaises au XVIII siècle. París, Colin.

MIRÓ, Gabriel (2008): Obras completas, III. Madrid, Fundación José Antonio de Castro.

ONTAÑón DE LOPE BlAnCh, Paciencia (1974): «Temática en Gabriel Miró», en François LóPEZ, Joseph Pérez, Noël SAlomon y Maxime CheVAlier, coords., Actas del Quinto Congreso Internacional de Hispanistas. Bordeaux, Universidad de Bordeaux, pp. 663-669.

Proust, Marcel (1971): Contre Sainte-Beuve. París, Gallimard.

- (1983): En busca del tiempo perdido, 5. La prisionera. Trad. Consuelo Berges. Madrid, Alianza. (2015): En busca del tiempo perdido, 1. Por el camino de Swann. Trad. Pedro Salinas. Madrid, Alianza.

RIERA, Carme (1988): «Gabriel Miró y el movimiento prerrafaelista», 1616: Anuario de la Sociedad Española de Literatura General y Comparada, 6-7, pp. 141-148.

STENDHAL (1817): Histoire de la peinture en Italie. París, P. Didot.

- (1906): De l'amour (Édition revue et corrigée, et précédée d'une étude sur les ouvres de Stendhal). París, Garnier frères.

(1955): Obras completas. Trad. Consuelo Berges. México, Aguilar.

TOULET, Paul-Jean (1986): Euvres complètes. París, Robert Laffont.

VAn PraAg-Chantraine, Jacqueline (1958): «Marcel Proust et Gabriel Miró», Synthèses, 144, pp. 285-296.

VIDAL, Raymond (1934): Gabriel Miró, Le style. Les moyens d'expression. Bordeaux, Féret et fils, 1964.

YoshidA, Jo (2004): «Bonheur», en Annick Boulllaguet y Brian C. Rogers, eds., Dictionnaire Marcel Proust. París, Honoré Champion, p. 160. 